tensive drugs, do not imply an increase in the levels of PAS in none of the groups, but they can produce a significant increase in the levels of PAD in normotensive patients.

\section{- Oral Presentation 54}

TITLE: Dental pulp stem cells combined with bioceramic scaffold for bone regeneration

AUTHORS: Ortega Asensio V, Pérez Corral I, Lois Franco A, Loughney González A, Fernández Domínguez M. Master en Cirugía Bucal e Implantología. Universidad San Pablo CEU. Madrid.

SOURCE: Med Oral Patol Oral Cir Bucal. 2015 June 1;20(Supplement1):S22.

* doi:10.4317/medoral.17643944

http://dx.doi.org/10.4317/medoral.17643944

Objective: To assess the advantages of the combined use of dental pulp stem cells (DPSCs), with a bioceramic scaffold for bone regeneration.

Material and Methods: For our study 3 mini-pigs were used, carrying 2 defects per shinbone (total of 12 defects). On the left side DPSCs were placed and guided bone regeneration was performed using resorbable collagen membranes. The right side is also filled with a biocomplex of DPSCs and bioceramic scaffold made of hydroxyapatite and tricalcium phosphate (Maxresorb $($ )).

Results: 3 months later, in the right shinbone a higher bone density was found, moreover the left bone defects weren't completely filled.

The osteon formation and maturation of bone found in the histological study was much higher in the right shinbones. It is confirmed by this study that the osteoconductive properties of the scaffold promote tissue differentiation to bone, promote adhesion to the surrounding bone and accelerate mineralization which is the keystone in the successful use of mesenchymal cells.

Conclusions: Bone regeneration using dental pulp stem cells significantly enhanced with the use of osteoconductive biomaterials.

The surgical management of DPSCs becomes easier.

\section{- Oral Presentation 55}

TITLE: Diascopy in pigmented lesions of the oral mucosa: is a reliable technique?

AUTHORS: Pérez López D, Luces González R, Martínez Balayo P, Peñamaría Mallón M, Otero Rey E, Blanco Carrión A.

Master de Odontologia Practica Diaria. University of Santiago de Compostela.
SOURCE: Med Oral Patol Oral Cir Bucal. 2015

June 1;20(Supplement1):S22.

* doi:10.4317/medoral.17643945

http://dx.doi.org/10.4317/medoral.17643945

Aim: To determine the reliability of diascopy in the differential diagnosis of oral pigmented lesions.

Material and Methods: A bibliographic search in Medline-Pubmed was carried out. All articles focused specifically on the application of this diagnostic technique, either on skin or in the oral cavity, were analised. Additionally, recent differential diagnosis protocols of oral pigmented lesions in which diascopy is applied were considered. Likewise, several clinical cases of oral pigmented lesions assessed in our dental care service are presented.

Results: There are not comparative studies that assess diascopy in relation to its diagnostic reliability. The main objective of this method is to determine the intravascular or extravascular location of the blood component in a supposed vascular lesion. The vast majority of recent diagnostic protocols continue recommending its use for this purpose.

Conclusions: Positive diascopy points out the existence of an intravascular lesion, while a negative result does not rule it out.

\section{- Oral Presentation 56}

TITLE: Study of mandibular lateral movement and condylar path in right-handed

AUTHORS: Pintos Pérez B; López Darriba I; Santana Penín U; Da Silva Domínguez L.

Department of Occlusion and Prosthetic Dentistry, Faculty of Odontology, University of Santiago de Compostela.

SOURCE: Med Oral Patol Oral Cir Bucal. 2015

June 1;20(Supplement1):S22.

* doi:10.4317/medoral.17643946

http://dx.doi.org/10.4317/medoral.17643946

Objective: this study seeks to determine if there is some relation between the manual dexterity in right-handed people, the condylar path inclination and the mandibular dynamic.

Material and Methods: A population of 58 odontology students from the University of Santiago de Compostela, all of them right handed, has been studied. Their mandibular dynamic has been evaluated and an extra oral registration of the condylar path has been effectuated with the Gerber's extra oral face bow, following the method described by Gysi.

Results: The results achieved for the mandibular dynamic have been the following: right laterality $8,345 \mathrm{~mm}$ $( \pm 2,0842)$, left laterality $9,293 \mathrm{~mm}( \pm 1,9669)$, protrusion 
$7,733 \mathrm{~mm}( \pm 1,8619)$, opening $45,422 \mathrm{~mm}( \pm 6,1572)$. The condylar path values have been $46,6925^{\circ}( \pm 7,53386)$ for the right side and $49,2299^{\circ}( \pm 7,97528)$ for the left one. Significant statistically differences have been found between the left and the right lateralities, being bigger the left one $(\mathrm{p}<0.000)$ and between the right and the left condylar path, being higher the left one $(p=0.009)$.

Conclusion: In the current study we find out that in the population studied, the lateral movement is bigger and the condylar path is higher on the left side.

\section{- Oral Presentation 57 \\ TITLE: Épulis fissuratum. A case report}

AUTHORS: Puente Fernández S, De la Calle Cañadas C, Martínez Rodríguez N, Fernández Cáliz F, Belarra Arenas C.

Máster en Cirugía Bucal e Implantología. Hospital Virgen de la Paloma.

SOURCE: Med Oral Patol Oral Cir Bucal. 2015

June 1;20(Supplement1):S23.

* doi:10.4317/medoral.17643947

http://dx.doi.org/10.4317/medoral.17643947

Introduction: Inflammatory fibrous hiperplasia or epulis fissuratum) is the most common lesion of soft tissue in the oral cavity. It is more frequent in females. It is an adaptive overgrowth located over the soft tissues of the vestibular sulcus or alveolar ridges caused by low intensity chronic irritation from poorly adapted prostheses. This lesion progresses to the formation of asymptomatic fibrous tissue.

Objective: The aim to this case is to describe the clinical characteristics and to establish the treatment of this lesion.

Case Report: A 68-years-old woman was referred to go to the Oral Surgery Hospital Virgen de la Paloma. She reported a tissue growth into the oral cavity located over left buccal mucosa. No relevant family and personal history. The intraoral examination revealed a pedunculated lesion $3 \times 4 \mathrm{~cm}$, whitish, appeared with a fibrous consistency and ulcerated surface. After informed consent, we proceeded to anesthesia in the region with an infiltrative local technical and subsequent cleavage by scalpel. Histopathological analysis showed dense connective tissue with few fibroblasts and blood vessels and this result confirmed epulis fissuratum. The patient returned one year later, without any signs of recurrence.

Conclusion: It is characteristic of epulis fissuratum the presence of a lesion in folds enlarged or elongated in the seat area of the prosthesis with an ulcerated or not surface and a color ranging from white to erythematous. Treatment involves surgical removal of the lesion and elimination of the causing factors always with appropriate prosthetic reconstruction (the denture must be remade or substantlly adjusted).

\section{- Oral Presentation 58}

TITLE: Oral patology in the Inflamatory Bowel diseases.

AUTHORS: Rio Rouco P. Gallas Torreira M. Barreiro De Acosta $M$.

Faculty of Medicine and Dentistry. University of Santiago de Compostela (USC).

SOURCE: Med Oral Patol Oral Cir Bucal. 2015

June 1;20(Supplement1):S23.

* doi:10.4317/medoral.17643948

http://dx.doi.org/10.4317/medoral.17643948

Objectives: To analyze the predominance of different oral pathologies in patients with Inflamatory Bowel diseases (IBDs), studying the distribution in patients with Crohn disease (CD) and ulcerative colitis (UC).

Material and Methods: A cross-sectional prevalence study was performed. The population of this study are patients with IBD including biological treatment pro-

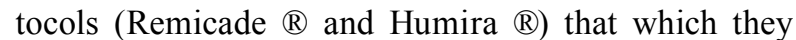
perform a basic clinical oral examination and a survey designed to detect oral pathology.

Results: Oral lesions affect 73,53\% of patients, $50 \%$ of patients present aphtae. gingival bleeding (49\%), gingivitis $(38,23 \%)$, periodontitis $(26,47 \%)$ and the pain of Temporo-Mandibular Joint (TMJ) (26,47 \%). The lesion with the lowest prevalenc are the oral/dental??? abscesses, $(11,76 \%)$. Exist an heterogeneous distribution between the patients with CD or with UC, the prevalences are predominant for the gingivitis $(32,35 \%)$, the periodontitis $(17,65 \%)$, the gingival bleeding $(38,8 \%)$ and ATM pain $(16,18 \%)$ in the CD, while in the UC more abscesses are presented $(7,35 \%)$. But only exist significantly statistically differents for gingival bleeding $(\mathrm{p}=0,028)$.

Conclusions: Oral diseases in IBD patients, treated with Remicade ${ }^{\circledR}$ and Humira ${ }^{\circledR}$ is high. Our results indicate the existence of oral pathology, although patients are being controlled with biological treatments and in periods of remission of their disease.

\section{- Oral Presentation 59}

TITLE: Perception of the "educational climate" in students from the university of Santiago de Compostela: medicine vs dentistry

AUTHORS: Romero González C, Ruiz Casalderrey D, Arce Vázquez VM, Casares de Cal MA, Palés Argullos J, Tomás Carmona I.

Oral Sciences Research Group. School of Medicine and Dentistry, University of Santiago de Compostela, Spain.

SOURCE: Med Oral Patol Oral Cir Bucal. 2015 June 1;20(Supplement1):S23. 